\title{
Factors contributing to spatial inequality in academic achievement in Ghana: Analysis of district-level factors using geographically weighted regression
}

\author{
David Ansong a, ${ }^{\text {, }}$, Eric K. Ansong ${ }^{\mathrm{b}}$, Abena O. Ampomah ${ }^{\mathrm{c}}$, Bernice K. Adjabeng ${ }^{\mathrm{d}}$ \\ ${ }^{\text {a } U n i v e r s i t y ~ o f ~ N o r t h ~ C a r o l i n a ~ a t ~ C h a p e l ~ H i l l, ~} 325$ Pittsboro Street, Chapel Hill, NC 27599, USA \\ ${ }^{\mathrm{b}}$ University of East London, UK \\ c University of Ghana, Legon, Ghana \\ ${ }^{\mathrm{d}}$ Webster University, St. Louis, USA
}

\section{A R T I C L E I N F O}

\section{Article history:}

Available online

\section{Keywords:}

Academic achievement

Spatial modeling

Educational inequalities

Ghana

\begin{abstract}
A B S T R A C T
Like most Sub-Saharan African countries, Ghana's basic educational system continues to undergo reform, receiving substantial investment to ensure all citizens have access to quality educational opportunities regardless of where they live. Although the reforms have markedly improved access to education at the junior high school level, the overall level of academic achievement among Ghana's population remains low, especially in deprived areas of the country. The low rate of achievement warrants examination because the lack of education hampers social mobility and constrains the ability of pupils from deprived communities to progress up the academic ladder. This study uses spatial modeling tools and district-level data to examine spatial variability in rates of academic achievement among districts in Ghana, and to investigate the differential effects of macro-level factors on academic achievement. Analysis reveals two key findings: (a) the existing pattern of spatial inequality primarily favors academic achievement of students in the Middle and Southern Belt regions of Ghana; and (b) factors contributing to academic achievement vary spatially, with the significance level, magnitude, and direction of relationship varying from one district to another. The study demonstrates the quintessence of an approach to educational development that emphasizes decentralization, thereby allowing educational investments and interventions to be tailored to local needs.
\end{abstract}

() 2015 Elsevier Ltd. All rights reserved.
A key to reducing poverty in Sub-Saharan African countries is ensuring the majority of the citizens of these countries have access to an appropriate and quality education. To meet this need, Ghana has undertaken reforms of the educational system by offering 9 years of free and compulsory basic education. Data from United Nations Development Program show that Ghana is on track to achieving $100 \%$ gross and net enrollment ratios at the primary education level by 2015 (UNDP, 2015). Despite this achievement, critical questions remain about the quality of basic education and the factors contributing to educational disparities across geographic regions of the country.

Progression to higher education is possible if students attain grades at the junior high school (JHS) level that allow them to

\footnotetext{
* Corresponding author.

E-mail addresses: ansong@email.unc.edu (D. Ansong), e.ansong@uel.ac.uk (E.K. Ansong), aoampomah@ug.edu.gh (A.O. Ampomah), badjabeng38@webster edu (B.K. Adjabeng).
}

qualify for senior high school (SHS) admission. Currently, academic achievement at the JHS level is generally low, putting many young Ghanaians at risk of failing to progress to SHS or beyond (Norviewu-Mortty, 2012). Data from 2006 to 2008 showed that more than a third of students who took the Basic Education Certificate Examination (BECE), which is a national standardized examination offered at completion of JHS, did not score high enough to qualify for SHS (Daily Graphic, 2008). A 2013 report by Ghana's Ministry of Education suggests that the transition rate from JHS to SHS has not exceeded 60\% since the late 1990s (Ministry of Education, 2013). Many stakeholders have also expressed concern about the low level of learning outcomes (Ansong, 2013; Degue, 2012; United Nations Economic Commission for Africa, African Union, African Development Bank, \& United Nations Development Programme, 2014).

The goal of this study is twofold: (a) to examine the spatial dimension of current academic achievement at the basic education level, and (b) to contribute to the knowledge-base from the macro 
and contextual lens by using district-level data to enrich the understanding of district level predictors of spatial disparities in academic achievement in Ghana. Although prior studies, particularly in the fields of geography and political economy, have highlighted spatial inequality in Ghana (Annim, Mariwah, \& Sebu, 2012; Senadza, 2012; Songsore, 2003), there are knowledge gaps in the empirical literature. Thus far, extant studies have stopped short of providing empirical insights into the macro factors that predictor academic achievement and whether their predictive power is spatially non-stationary. To contribute to the current body of work, we employ a data analytic strategy that allows us to investigate possible geographical differences in the bivariate relationships between academic achievement and their district level predictors and thereby, shed light on the whether the predictors of poor performance in one area are necessarily the same in another area of the country. Another critical gap in the extant literature is that nearly all education research on academic success at the basic education level in Ghana have examined outcomes and predictors at the student-level but ignored the district level. Our perspective is that it is important to situate the current body of knowledge in the larger contextual domain in which crucial policy and program decisions are made.

\section{Theoretical considerations}

What distinguishes this study from other educational outcomes research in Ghana is the emphasis on district-level outcomes and predictors. The theoretical approach underlying an investigation of district-level factors stems from the idea of structural level neighborhood effects championed by urban sociologists of the classical Chicago school. This perspective emphasizes the implications of macro-level predictors on a variety of macro-level outcomes (Sampson \& Morenoff, 1997). In particular, Sampson (2008) has extensively researched the overwhelming and disproportional emphasis on individual-level outcomes as compared with research that considers macro-level outcomes, contending that "dual scholarly interventions [both individual and macro-level] move the field forward by providing new analyses, new insights, needed clarifications, and most important, an opportunity to reconsider the very idea of neighborhood effects" (p. 192). This study responds to Sampson's call for research to pursue new analyses and insights into "neighborhood effects" by focusing on a district-level outcomes and predictors.

There are compelling policy reasons for educational research in Ghana to give serious attention to macro units (e.g., districts and regions). Ghana's decentralized education management structure places the responsibility for educational decisions with the District Assemblies and district education offices (Maikish \& Gershberg, 2008). District Assemblies' are responsible for the distribution of funds to district schools for furniture, school buildings, and related infrastructural needs in accordance with the districts' priorities. A significant portion of these funds comes from the District Assembly Common Fund, which is revenue from the Central Government. Given that central administrative authority and major public expenditure on education are devolved to the district level (Maikish \& Gershberg, 2008), it is critically important that education research does not ignore either district-level outcomes or their predictors that inform major public expenditure and investments.

\section{Spatial inequality in educational outcomes}

Although academic achievement is generally low in Ghana, the problem appears to be more acute in some geographical areas, especially rural, disadvantaged areas (Senadza, 2012). The expectation that universal access to education will provide a viable path out of poverty may not be realized if geographical disparities exist in either the quality of education available to students or how well students perform academically. Generally, access to life enhancing resources in Ghana is unequally divided along an imaginary line between Northern and Southern Belts (Varly, Cummiskey, Kline, \& Randolph, 2014). Successive governments in Ghana have pursued targeted programs and strategies to narrow the economic gaps between the Northern and Southern Belts. The most recent effort is the establishment of the Savannah Accelerated Development Authority (SADA) aimed at reducing the incidence of poverty to less than $20 \%$ in 20 years and doubling incomes in the Northern belt (SADA, n.d.).

The regional divide and economic gap is also reflected in student academic achievement rates with the poorest performing schools clustered in rural and economically deprived areas (NorviewuMortty, 2012). Results of the 2013 National Education Assessment showed the percentage of students who achieved proficiency in math and English was 3 times greater in the Greater Accra region (in the Southern Belt) than in the Northern Belt regions (Varly et al., 2014). In 2007, about $48 \%$ of the 320,235 JHS students who took the BECE failed to obtain sufficient grades to qualify for senior high school, with most of the unsuccessful candidates coming from rural and deprived areas across the country (Norviewu-Mortty, 2012).

Overall, the Northern regions of Ghana are under-resourced and substantially poorer as compared with the other regions of the country. Nearly two-thirds of Northern Belt residents are considered poor, whereas only a fifth of those in the Southern Belt are poor (Kunateh, 2011). The ongoing poverty discussion in Ghana suggests that indicators of poor educational achievement in deprived areas reflect the spatial disparity in economic and other social development indicators (Ansong \& Chowa, 2013). However, it is unclear whether the predictors of academic outcomes are the same in all regions or districts of the country.

To address this research gap, the present study (a) examined the nature of academic achievement at the district level, (b) identified key district-level predictors of academic achievement, and (c) determined the extent of spatial inequalities in the relationship between academic achievement and the associated district-level predictors. By establishing whether poor academic achievement is a nationwide issue or an isolated problem in certain areas, and revealing whether the predictors of academic achievement are spatially non-stationary, this study has the potential to make an important contribution in the shift towards more contextualized policy responses to educational needs in Ghana.

\section{Factors contributing to inequality in educational outcomes}

The neighborhood effects framework emphasizes that differences in neighborhood characteristics are the key factors influencing the production and reproduction of neighborhood outcomes (Duncan \& Raudenbush, 1999). In the following section, we discuss several interconnected factors suggested by both theory and empirical studies as having the potential to affect disparities in the educational system (Rodríguez-Pose \& Tselios, 2011).

The rate of labor force participation is associated with educational inequality (Doro, 2008), with the direction of the relationship dependent on household size (Barnes, Green, Orton, \& Bimrosete, 2005). In general, the expectation is that higher rates of household employment will increase access to disposable household income that can be used for education-related costs, including supplies, services such as afterschool programs, and transportation to and from school. The potential negative effects of household unemployment or underemployment can be exacerbated by other sociodemographic factors such as lower levels of human capital (i.e., educational attainment) (Eccles \& Davis-Kean, 2005) and large 
household size (Downey, 1995). The effect of large household size on academic achievement is explained by the resource dilution model, which suggests that as the number of children in the household increases so does the demand on household resources, and thereby limiting the amount of parenting time and financial resources available to each child (Downey, 1995).

Urbanization is another factor that can contribute to inequality in educational outcomes. Because urban areas tend to have a greater concentration of both well-educated parents and highskilled labor, income levels tend to be substantially higher than in rural areas, and therefore, many urban families are in a financial position to afford their children's educational needs (Glaeser, 1999). In addition, as compared with rural families, residents of urban areas have more choices and better quality options for their children's education, including higher quality schools, better infrastructure, and greater access to information - all of which are known to affect educational outcomes (Ludwig, 1999; Wheeler, 2004). However, the concentration of educational resources and supports in urban areas underscores the persistent rural-urban inequality of Ghana's educational system. For example, urban areas have reliable systems providing some of the schools with electricity and high-speed Internet connections (Dave, 2013).

The objectives of this study were to identify and examine spatial variability in academic achievement and their determinants at the district level in Ghana. We recognized that it was possible that educational outcomes and their drivers might differ across districts because of varying needs, investments, and composition of individual districts. Thus, we hypothesized that academic achievement would vary geographically, and the factors contributing to academic achievement would vary between districts. Ascertaining whether the drivers of academic achievement are location-specific is valuable information for promoting a contextual understanding of educational needs in Ghana. Such insight could be especially important to policy makers and development agencies that are in positions to improve tailored programs, service delivery, and policies.

\section{Data and variables}

Data analyzed in this study were derived from three sources. Data on academic achievement is based on the 2013 BECE result compiled by the Ghana Education Service. Data on school characteristics were obtained from the Ministry of Education. The remaining data on household size, urbanization, employment rate, literacy rate, and electricity connectivity were obtained from the 2010 population and housing census data published by the Ghana Statistical Service (2012).

\section{Dependent variable}

The dependent variable used in this study was academic achievement. This was measured as the percentage of candidates who passed the BECE, and therefore, qualified for admission to SHS. Possible BECE scores range from 6 to 54 . A passing score is quantified as earning an aggregate score between 6 and 30, with 6 being a "perfect" score (Mereku, 2012). We chose this measure as our dependent variable because it is a nationally recognized yardstick that determines a student's proficiency at the basic educational level, and used as a qualification for admission to SHS. Candidates who earn a qualifying score and who wish to enroll in SHS will be admitted if open slots are available.

\section{Explanatory variables}

Explanatory variables modeled in this study were based on the factors that predict academic performance discussed earlier in this paper. The variable school congestion index is a measure based on the number of pupils in the classroom and the extent to which classrooms are crowded. We used principal component analysis (PCA) to create a linear combination of three congestion indicators: pupil to trained teacher ratio, pupil to untrained teacher ratio, and class size (Abraha et al., 1991; Michaelowa, 2001). The factor loadings of the three indicators ranged from .69 to .93, and accounted for $62 \%$ of the variance in the index. The variable pedagogical resource index quantifies both the teaching and learning resources available to schools in a district. The index encompasses five indicators: number of math, English, and science textbooks per student, number of seating places per student, and number of writing places per student (Chowa, Masa, Wretman, \& Ansong, 2013; Etsey, 2005). Together, the five indicators explained $50.12 \%$ of the variance in the index, with factor loadings ranging from .53 to .87.

The variable household size reflected the structure of households in a district, and it was measured as the number of people living in a household. The urbanization variable was a measure of the proportion of a district's population living in urban areas. The electricity connectivity variable quantified the electrical grid supplying power within a district. This measure was defined as the number of households within a district that used electricity for lighting. In this study, we defined literacy rate as the percentage of adult residents of a district who are able to read and write a simple sentence with understanding in any language. The variable employment opportunities was defined as the percentage of a district's economically active population (i.e., 15-60 year olds) engaged in paid employment.

\section{Data analysis procedures}

Spatial autocorrelation analysis of academic achievement

To address the first research question of whether geographical inequalities exist in academic achievement across Ghana, we used Moran's I test to investigate for spatial autocorrelation in the academic achievement variable. The Moran's I test evaluates whether the pattern of academic achievement is clustered, dispersed, or random. We conducted a multidistance spatial cluster analysis using the Ripley's K-function tool in ArcGIS Desktop to guide the selection of appropriate distance at which to test possible clustering or dispersion of academic achievement.

\section{Analysis of spatially varying relationships}

To determine whether the direction and magnitude of the relationships between academic achievement and the set of nine independent variables varied by locality, we computed and compared two analytical approaches: ordinary least squares (OLS) regression and geographically weighted regression (GWR). In contrast to OLS regression, GWR assumes that the relationship between the dependent and independent variables is not constant across the study area. We ran a GWR ANOVA test to determine if the GWR (local) model performed significantly better than the traditional (global) regression model (Fotheringham, Brunsdon, \& Charlton, 2002).

We calibrated and validated all spatial statistical models with the GWR 4.0.77 software developed by Nakaya (2014). We also used the Moran's I test and created thematic maps with ArcGIS Desktop 9.2. Because the dependent variable was a continuous variable with normal distribution, we ran a semiparametric Gaussian GWR model specified as follows: 
Academic achievement $=\beta_{0}\left(X_{i}, Y_{i}\right)+\beta_{1}\left(X_{i}, Y_{i}\right)$ household size

$$
\begin{aligned}
& +\beta_{2}\left(X_{i}, Y_{i}\right) \text { Male employment } \\
& +\beta_{3}\left(X_{i}, Y_{i}\right) \text { Female employment } \\
& +\beta_{4}\left(X_{i}, Y_{i}\right) \text { Urbanization } \\
& +\beta_{5}\left(X_{i}, Y_{i}\right) \text { Electricity connectivity } \\
& +\beta_{6}\left(X_{i}, Y_{i}\right) \text { Male literacy } \\
& +\beta_{7}\left(X_{i}, Y_{i}\right) \text { Female literacy } \\
& +\beta_{8}\left(X_{i}, Y_{i}\right) \text { Pedagogical resource index } \\
& +r_{1} \text { Classroom congestion index } \\
& +\varepsilon_{i}
\end{aligned}
$$

where $X_{i}$ and $Y_{i}$ are projected $\mathrm{x}-\mathrm{y}$ coordinates. Note that classroom congestion is modeled as geographically invariable based on results of the geographical variability tests of local coefficients. We used adaptive bandwidth to select the optimal bandwidth size. The significance of our choice of adaptive bandwidth is that it makes the necessary adjustments to the bandwidth size depending on the population density (i.e., dense vs. sparse) of the local area (Nakaya, 2014).

To illustrate the geographical variability in the significance level, magnitude, and direction of the final parameter estimates, we used ArcGIS Desktop 9.2 to generate eight thematic maps to illustrate the spatial distribution of the parameter estimates. We also generated a map for the regression residuals to demonstrate the sufficiency of the final models, and a second to display the R-squared values to demonstrate the spatial variability in the explanatory power of the final model.

\section{Results}

\section{Descriptive characteristics of districts}

In this study, we used Ghana's 2008 district boundaries that defined 170 districts. Ghana has a population of approximately 24.3 million and a total size of $238,535 \mathrm{~km}^{2}$. District sizes range from $122 \mathrm{~km}^{2}$ to $10,787 \mathrm{~km}^{2}$. Based on the 2010 population census, the most densely populated district was the Kumasi metropolitan area in the Asante region $(2,035,064$ people) followed by Accra metropolitan area in the Greater Accra region (1,848,614 people). Both of these districts are located in the Southern Belt of Ghana. The least populated districts were Dormaa East in the Brong Ahafo region in the Middle Belt (50,871 people) followed by Lambussie Karni in the Upper West Region in the Northern Belt $(51,654$ people).

On average, $45 \%(S D=20.81)$ of candidates from each district earned a passing score on the BECE. In about two-thirds of the districts, less than $50 \%$ of candidates earned a passing score; in other words, more than half of the candidates in the majority of the districts did not earn sufficient grades to qualify for entry into senior high. This observation is consistent with findings of prior studies and media concerns about low academic achievement in Ghana, especially at the basic education level (Etsey, 2005). Overall, the Southern and Middle Belts of the country outperformed the Northern Belt in academic achievement, as measured by the percentage of candidates who passed the BECE. The 10 top-performing districts are in either the Southern or Middle Belt. On the other hand, 6 of the 10 worse-performing districts are in the Northern Belt.

Pedagogical resources and infrastructure are essential to quality education. In Ghana, educational resources are insufficient, although the extent of inadequacies varies by district. The average class size of districts was about 36 pupils $(S D=11.45)$ but nearly $75 \%$ of the districts had average class sizes that exceeded 30 students. The Garu Tempane district in the Upper East region of the Northern Belt had the largest average class size of 81 students. In terms of school furniture, on average, all districts in Ghana have more students enrolled than the number of available classroom seats (chairs; $M=.87, S D=.26$ ) and writing spaces (desks; $M=.83$, $S D=.29$ ). Only $16 \%$ of districts had at least one chair per student, of which $42 \%$ were in the Northern Belt. Similarly, writing desks are insufficient for the number of enrolled students. Only $13 \%$ of the districts had at least one desk per student, and most of those districts (59\%) were in the more sparsely populated Northern Belt. The fact that the overwhelming majority of districts have insufficient seating and writing spaces could have negative implications for effective learning and teaching. Many pupils either go without seating and writing places or bring their own furniture to school (Asiamah, 2010). As prior studies in Ghana have shown, lack of a school desk and chair is a major disincentive to schooling (Akyeampong, Rolleston, Ampiah, \& Lewin, 2012). Other pedagogical resources such as textbooks are also inadequate. Whereas the ideal textbook-to-student ratio would be 3.0 because this ratio takes into account textbooks for three subjects (i.e., math, English, and science) the average textbook-to-student ratio was 1.45 $(S D=.35)$. The highest ratio was 2.43 (Karaga district in the Northern Belt) and the lowest was .62 (Krachi West in the Southern Belt).

\section{Evidence of spatial inequality in academic achievement}

Results of the Moran's I test (spatial autocorrelation analysis) are illustrated in Figs. 1 and 2. The Moran's I test revealed that the percentage of students who achieved BECE scores between aggregate 6 and 30 (i.e., a passing score grade) were statistically significantly clustered: $(\mathrm{M}(i)=.29, \mathrm{Z}$-Score $=7.32, p<.01)$. Thus, we rejected the null hypothesis that academic achievement is not

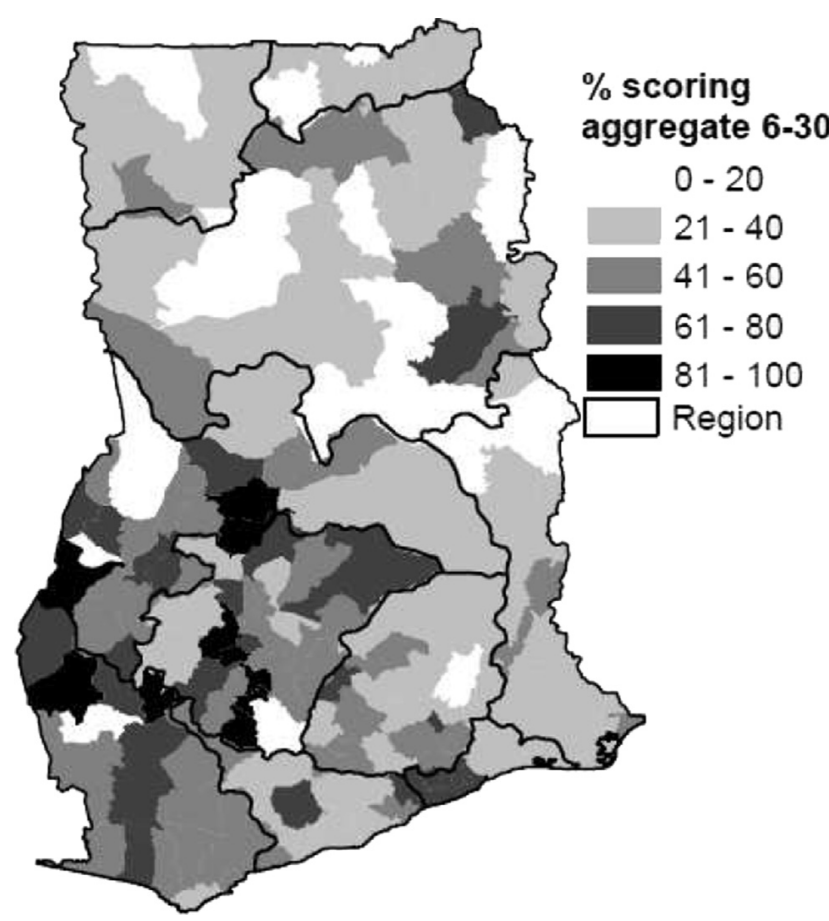

Fig. 1. Spatial distribution of percentage of candidates that earned aggregates $6-30$. 


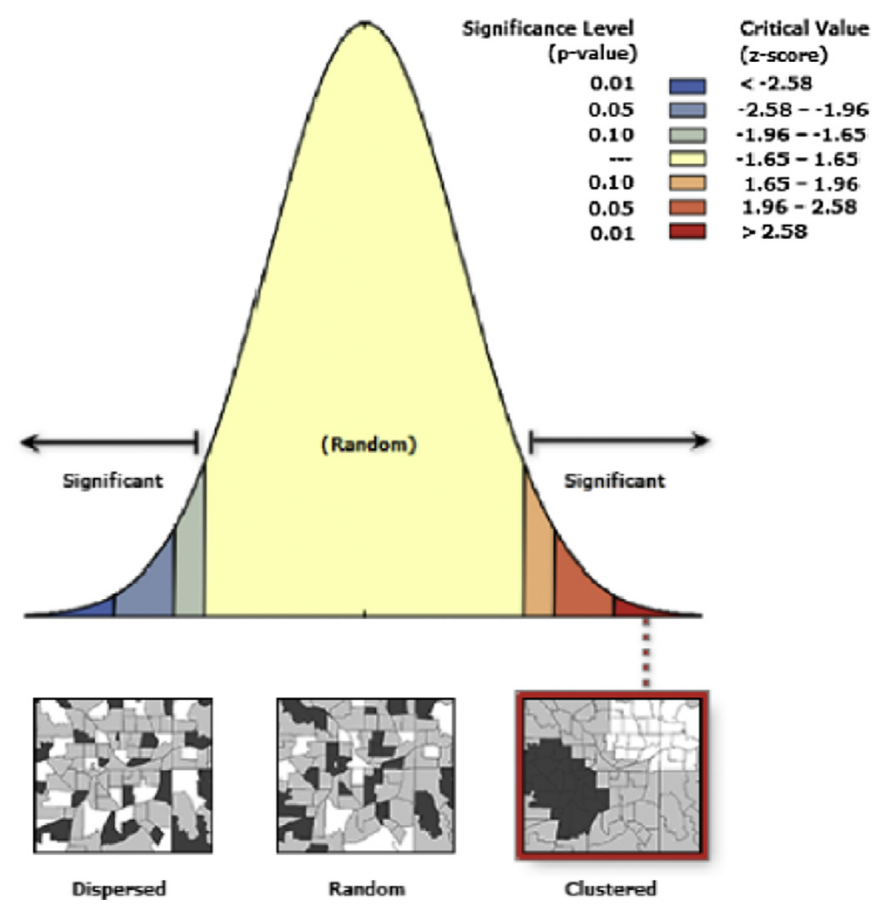

Fig. 2. Results of spatial autocorrelation (Moran's I).

clustered in the study area. The statistical significance at the .01 level means there is less than a $1 \%$ chance that the clustered pattern of academic achievement is the result of random chance. The graphical evidence of this pattern of academic achievement is show in Fig. 1.

\section{Relationships between academic achievement and drivers}

Global estimates and model fit

Results of the OLS model are shown in far right column of Table 1 . The OLS model explained $16.53 \%$ of the variance in academic achievement (Adjusted $R^{2}=.1653$ ), and 6 of 9 explanatory variables were not significantly associated with academic achievement. Specifically, the significant relationships shown in the OLS regression models indicated that, overall, household size $(b=-5.05, p<.05)$ and female employment $(b=-1.09, p<.001)$ were negatively associated with academic achievement; however, male employment $(b=0.93, p<.05)$ was positively associated with academic achievement.
The global OLS results might not adequately reflect the true nature of the relationships in various areas across districts because OLS does not account for geographical variability in the parameter estimates. This shortcoming and the results of our Moran's I test that suggested spatial differences in academic achievement provided the impetus to use GWR to account for spatial variability. As compared to the OLS model, the GWR model was a significant improvement based on three criteria. First, the GWR model increased the amount of variance explained by nearly $12 \%$ points, yielding $28.08 \%$ variance explained. Second, the GWR model provided a better fit to the data because the Akaike information criterion (AIC) score for the GWR model (1464.46) was lower than the AIC score for the OLS model (1485.71). The 21-point difference between the two AIC scores is well above the generally accepted cutoff of 3 points or greater (Jiang \& Xu, 2014). Last, results of the ANOVA test (see Table 2) confirmed that the performance of the GWR model was statistically significantly superior to that of the OLS model.

\section{Spatial patterns of local estimates}

The spatial distribution of the local $R^{2} \mathrm{~S}$ is graphically represented in Fig. 3. The values of the local $R^{2}$ s show how well the model fits the data in each district. The range of the local $R^{2} \mathrm{~s}$ (i.e., .2276 to .4589 ) demonstrates that the explanatory power of the model varies by districts. However, there is no clear regional or north-south pattern in the graphical presentation of the local $R^{2}$ values, which suggests that the model fits the data reasonably well, regardless of whether a subject lives in the Northern, Middle, or Southern Belt of the country. The spatial distribution for GWR model residuals in Fig. 4 shows no clear pattern of over or under prediction. The adequacy of our final GWR model is further verified by the statistically nonsignificant Moran's I test result: $\mathrm{M}(i)=.01, \mathrm{Z}$ Score $=0.47, p=.64$.

To determine whether each explanatory variable showed significant geographical variability, we conducted a geographical variability test of local coefficients. Results of the test are presented in Table 3. Results of the calibration model in the table showed that the classroom congestion index had a positive value greater than 2 , which suggested the impact of classroom congestion did not vary significantly across space. Thus, it was better to model the global coefficients of classroom congestion index. Results of the validation model in the third column of Table 3 confirmed that the relationships between academic achievement and the other eight explanatory variables were not uniform across all districts, and therefore, these variables should to be modeled as local terms.

Table 1

Geographically varying (local) and global results.

\begin{tabular}{|c|c|c|c|c|c|c|}
\hline \multirow[t]{2}{*}{ Variable } & \multicolumn{5}{|l|}{ Local results } & \multirow{2}{*}{$\frac{\text { Global results }}{\beta(S E)}$} \\
\hline & Mean of $\beta \mathrm{s}$ & $S D$ of $\beta \mathrm{s}$ & Min & Max & Median & \\
\hline Intercept & 69.28 & 14.54 & 40.44 & 98.19 & 73.11 & $64.42(10.16)^{* *}$ \\
\hline Household size & -5.61 & 1.94 & -9.24 & -1.81 & -5.77 & $-5.05(1.71)^{*}$ \\
\hline Urbanization & 0.02 & 0.14 & -0.31 & 0.27 & 0.03 & $0.06(0.09)$ \\
\hline Male employment & 0.78 & 0.48 & -0.13 & 1.30 & 0.99 & $0.93(0.33)^{*}$ \\
\hline Female employment & -0.90 & 0.44 & -1.42 & 0.21 & -1.06 & $-1.09(0.36)^{* *}$ \\
\hline Electricity connectivity & 0.26 & 0.26 & -0.11 & 0.81 & 0.24 & $0.15(0.18)$ \\
\hline Male literacy & 0.22 & 0.46 & -0.73 & 1.38 & 0.09 & $0.17(0.39)$ \\
\hline Female literacy & -0.28 & 0.54 & -1.63 & 0.54 & -0.09 & $-0.11(0.44)$ \\
\hline Pedagogical resource index & 0.50 & 1.02 & -1.02 & 3.27 & 0.33 & $0.87(1.58)$ \\
\hline Classroom congestion index & - & - & - & - & - & $2.69(1.76)$ \\
\hline Adjusted $R^{2}$ & 0.2808 & & & & & 0.1653 \\
\hline Akaike information criterion & 1464.46 & & & & & 1485.71 \\
\hline
\end{tabular}

Note. $S D=$ standard deviation; $S E=$ standard error ${ }^{*} p<.05,{ }^{* *} p<.01,{ }^{* * *} p<.001$. 
Table 2

Comparison of ordinary least squares and geographically weighted regression models.

\begin{tabular}{lllll}
\hline Source & SS & \multicolumn{1}{c}{$d f$} & MS & \multicolumn{1}{l}{$F$} \\
\hline Global residuals & $57,126.49$ & 159.00 & & \\
GWR improvement & $13,361.97$ & 17.53 & 762.44 & \\
GWR residuals & $43,764.53$ & 141.48 & 309.35 & $2.46^{* * *}$ \\
\hline
\end{tabular}

Note. GWR = geographically weighted regression; $S S=$ sums of squares; $d f=$ degrees of freedom; $M S=$ means squares; ${ }^{* * *} p<.001$.

\section{Variations in local estimates}

The maps in Figs. 5-12 show the local coefficients of the relationship between the academic achievement and the eight explanatory variables that have significant spatially varying effects. In the maps, the hash marks indicate the local coefficient for that district is not statistically significant at the .05 significance level. The red gradients (in the web version) represent inverse relationship between the dependent and explanatory variables whereas the blue gradients (in the web version) represent positive relationships. The darker the gradient, the larger the local coefficient value. Next, we present how each of the eight variables are associated with academic outcomes across different districts.

\section{Household size and academic achievement}

In many districts, larger household sizes are associated with lower academic achievement. Across all districts, the direction of the relationship between household size and academic achievement was negative (represented by red gradients in Fig. 5). The local coefficients range from -1.81 to -.9 .24 , as shown in Table 1 . In contrast to the global OLS estimate $(b=-5.05, p<.05)$, which suggested a negative relationship for the entire study area, the GWR results revealed that $58 \%$ of the local coefficients were not statistically significant at the .05 significance level. Many of the nonsignificant coefficients are in the Midwestern region of Ghana, whereas most of the significant local estimates are in the Upper East and West regions.

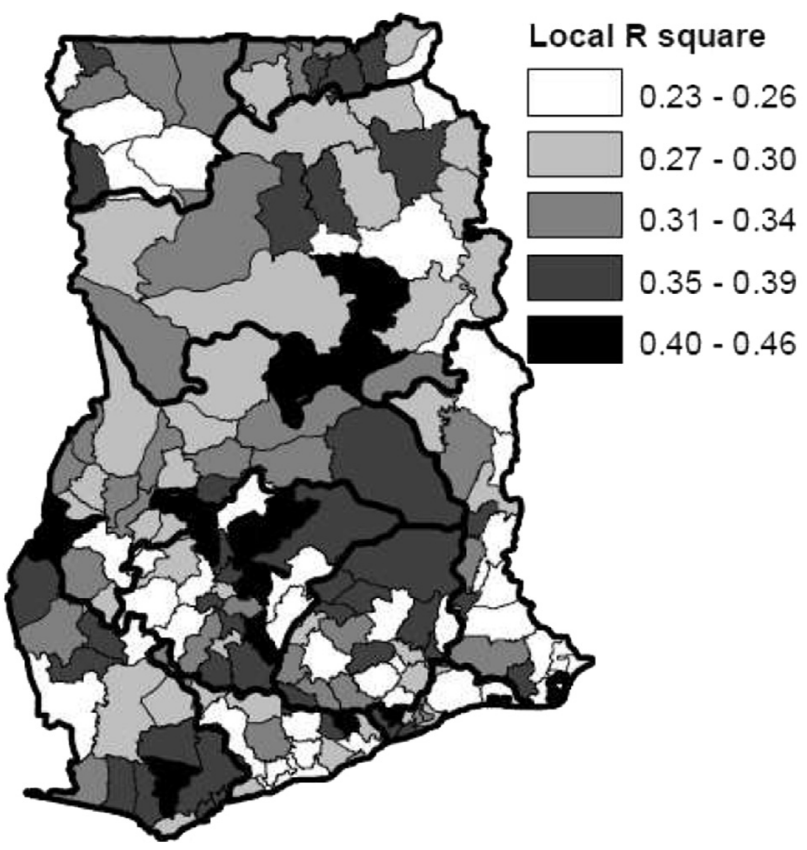

Fig. 3. Spatial distribution of local $R^{2}$ values.

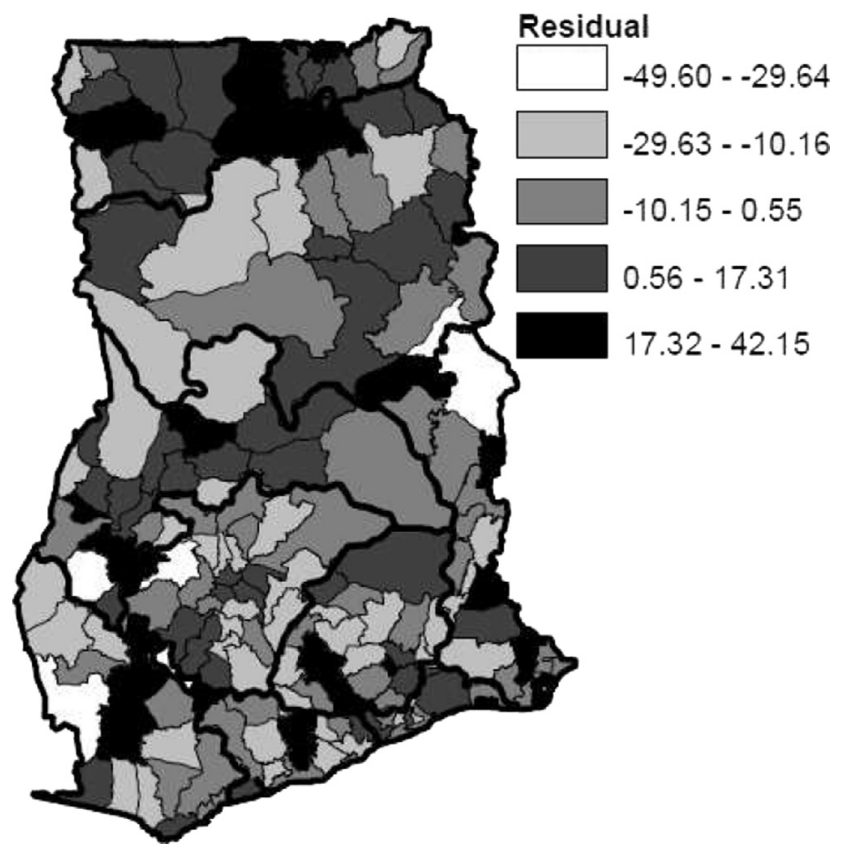

Fig. 4. Spatial distribution of residuals.

Urbanization and academic achievement

The global OLS estimate suggests that overall, urbanization is not significantly associated with academic achievement $(b=0.06$, $p>.05)$. However, the GWR results reveal that the local estimates are statistically significant in $17 \%$ of the districts. In other words, in about a fifth of the districts, a person would be able to predict the percentage of candidates who earned a passing BECE score by knowing the proportion of the population living in urban centers within the district. Fig. 6 shows that, overall, the relationship is trending in the positive direction because most of the districts are shaded blue. However, the percentage of urban population is positively and significantly related to academic achievement in only $10 \%$ of the districts. Most of these significant positive relationships are in the Middle Belt. In contrast, the relationship is negative in about $6 \%$ of the districts. That is, in about 10 districts, the larger the urban population in the district, the lower the number of candidates who earned passing scores on the BECE to qualify for senior high school. These 10 districts are predominantly in Northern Ghana.

Electricity connectivity and academic achievement

At the .05 significance level, the global OLS estimates of the relationship between electricity connectivity and academic achievement is not statistically significant $(b=0.15, p>.05)$, but the

Table 3

Geographical variability tests of local coefficients.

\begin{tabular}{|c|c|c|}
\hline \multirow[t]{2}{*}{ Variable } & \multicolumn{2}{|c|}{ Difference of criterion ${ }^{a}$} \\
\hline & Calibration model & Validation model \\
\hline Intercept & -25.40 & -17.65 \\
\hline Household size & -14.70 & -24.83 \\
\hline Urbanization & -9.15 & -9.94 \\
\hline Male employment & -37.94 & -28.64 \\
\hline Female employment & -28.57 & -26.44 \\
\hline Electricity connectivity & -5.20 & -4.86 \\
\hline Male literacy & -48.04 & -36.34 \\
\hline Female literacy & -1141.17 & -643.71 \\
\hline Pedagogical resource index & -5.85 & -5.00 \\
\hline Classroom congestion index & 1.79 & \\
\hline
\end{tabular}

${ }^{\text {a }}$ Note. A value $>2$ suggests no spatial variability. 


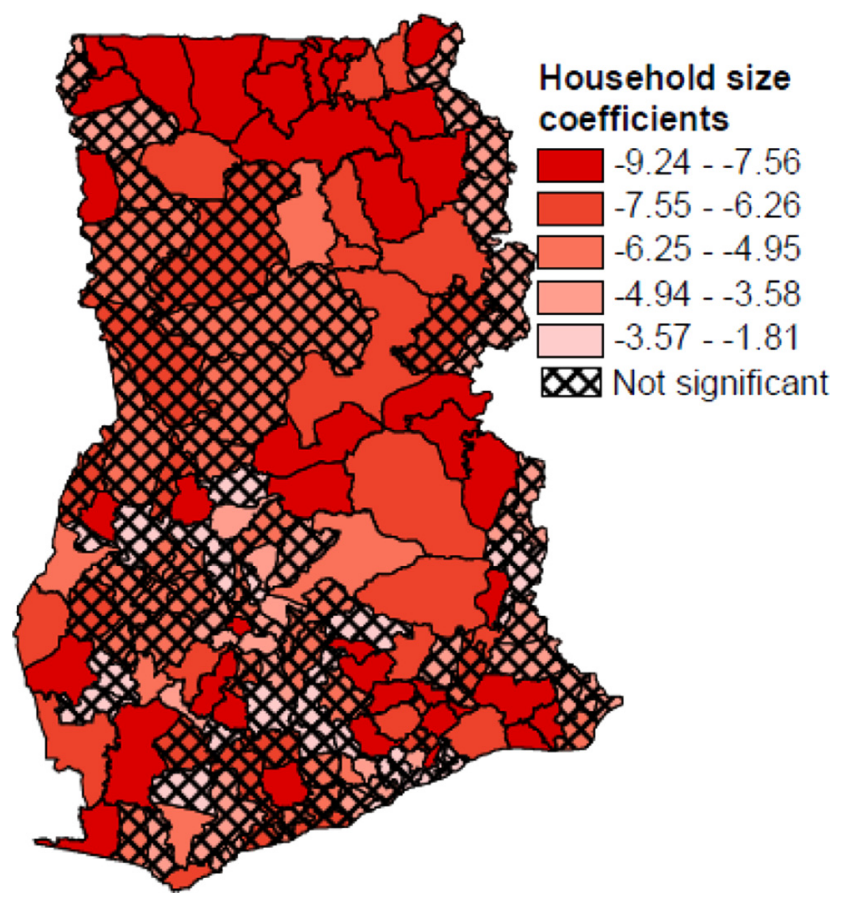

Fig. 5. Association between household size and academic performance.

variables are positively and statistically associated in $20 \%$ of the 170 districts. The statistically significant local coefficients range from 0.19 to 0.26 (shown in Fig. 7 ). In those 34 districts, for every one percentage increase in the number of households connected to electricity, the percentage of candidates who achieved a passing score on the BECE goes up by $0.19-0.26$ percentage points.

\section{Pedagogical resources and academic achievement}

According to the global OLS estimates, no statistically significant relationship exists between pedagogical resources and academic achievement at the district level $(b=0.87, p>.05)$. Similarly, results

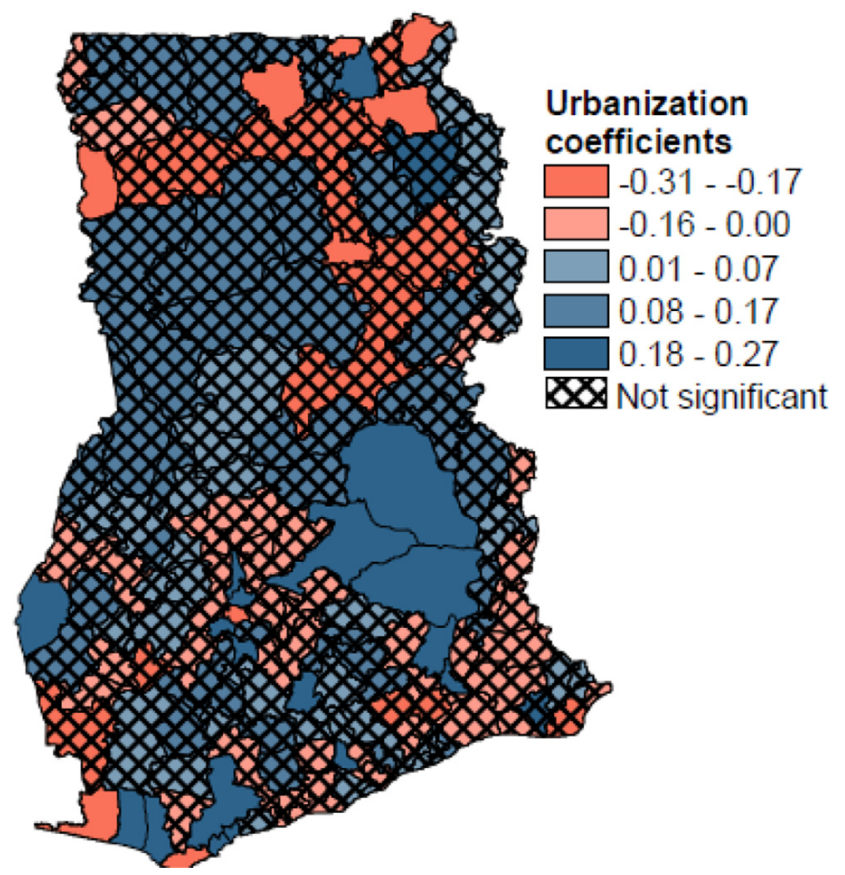

Fig. 6. Association between percentage of urban population and academic performance.

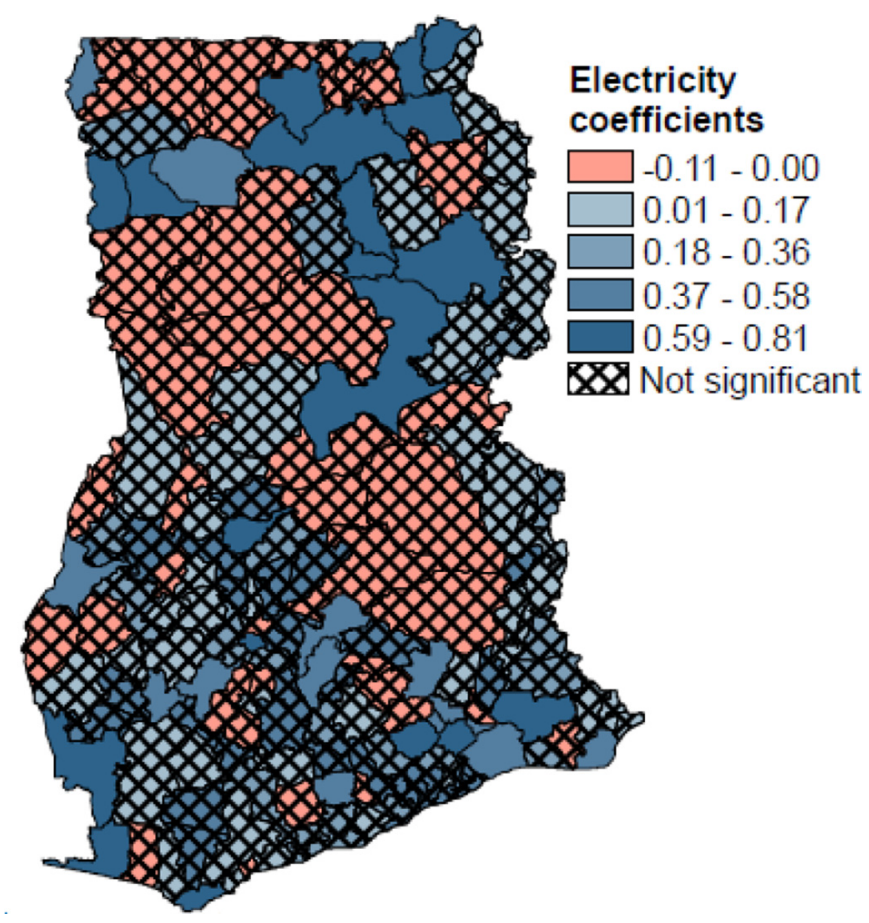

Fig. 7. Association between electricity connectivity and academic performance.

of the local GWR estimates ( $b=3.27$ to -1.02 ), as shown in Fig. 8, indicate no statistically significant relationship exists between pedagogical resources and academic achievement at the .05 significance level. Although the directions of the nonsignificant relationships are mixed, the relationships in a majority of the districts (64\%) are trending in the positive direction. Most of these trends are in the Northern Belt.

Adult male employment and academic achievement

The global OLS estimate of the relationship between adult male employment and academic achievement is statistically significant

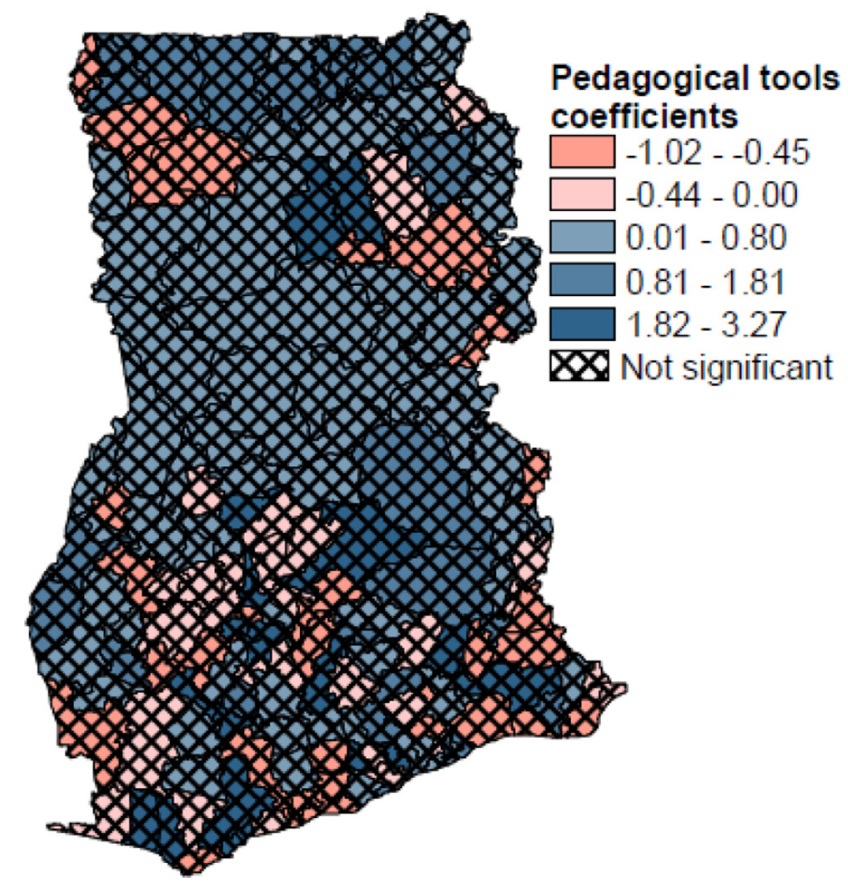

Fig. 8. Association between pedagogical tools and academic performance. 


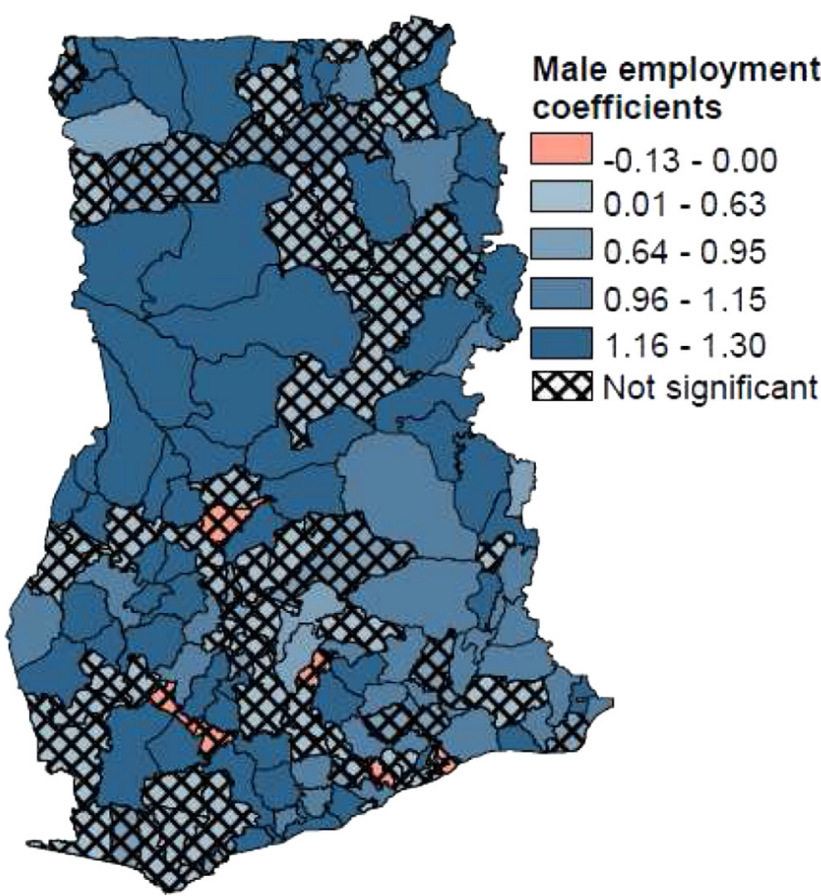

Fig. 9. Association between male employment and academic performance.

( $b=0.93, p<.05)$. However, when examined at the district level, this relationship is positive and significant in just more than half (55\%) of the districts, with the local coefficients ranging from 0.89 to 1.30 (See Fig. 9).

Adult female employment and academic achievement

The global OLS regression results suggests a statistically significant inverse relationship exists between adult female employment and academic achievement $(b=-1.09, p<.01)$. However, the local GWR results reveal that this inverse relationship is statistically significant in $45 \%(n=76)$ of the districts, most of which are located

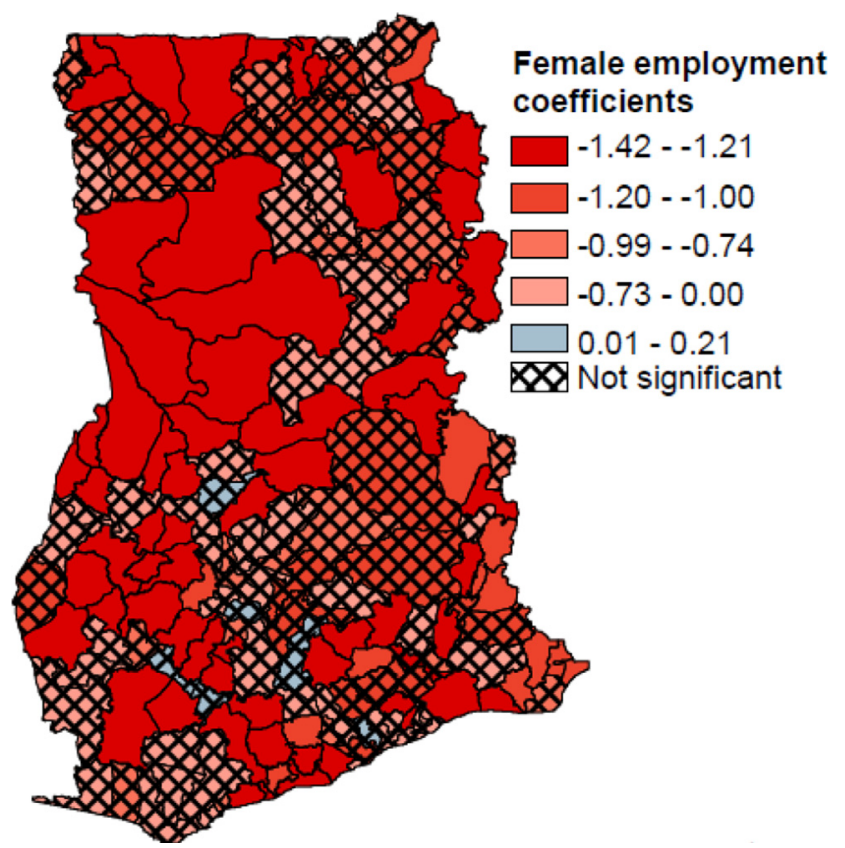

Fig. 10. Association between female employment and academic performance.

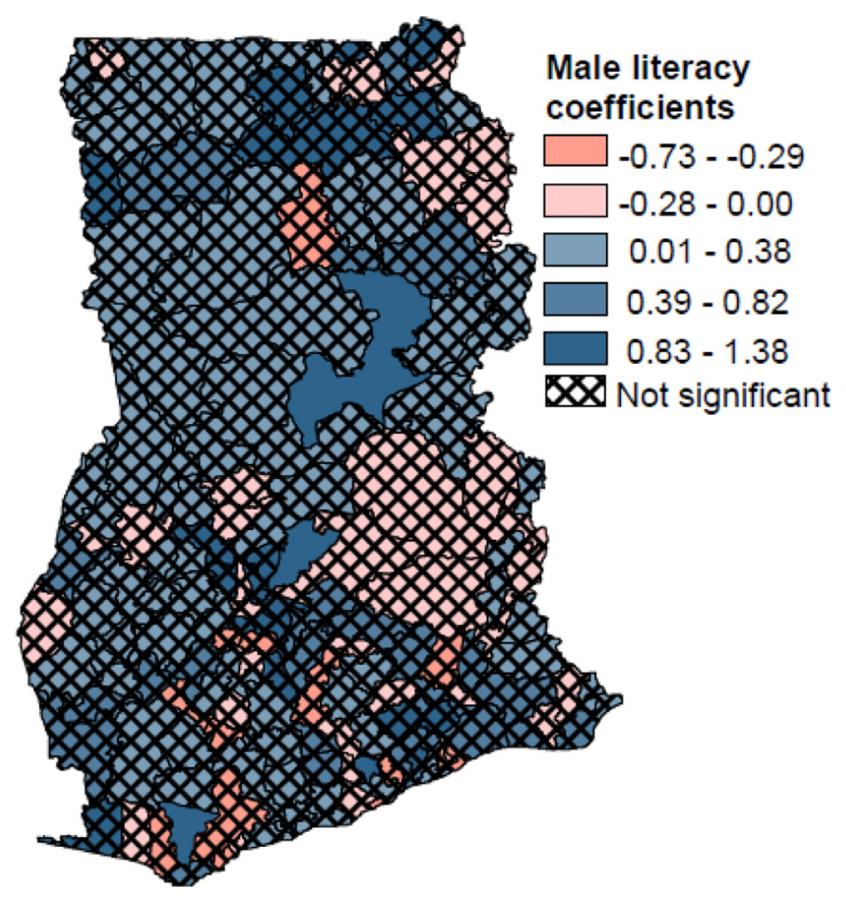

Fig. 11. Association between male literacy and academic performance.

in the western region, as shown in Fig. 10. The statistically significant local coefficients range from -0.54 to -0.65 . This finding means that for nearly half of Ghana's districts, a one percentage increase in the employment of economically active females is associated with a $0.54 \%-0.65 \%$ decrease in the percentage of candidates who earned passing scores on the BECE and qualified for senior high school (i.e., aggregates 6-30).

\section{Male literacy and academic achievement}

The global OLS regression test suggests there is no statistically significant relationship between adult male literacy and students'

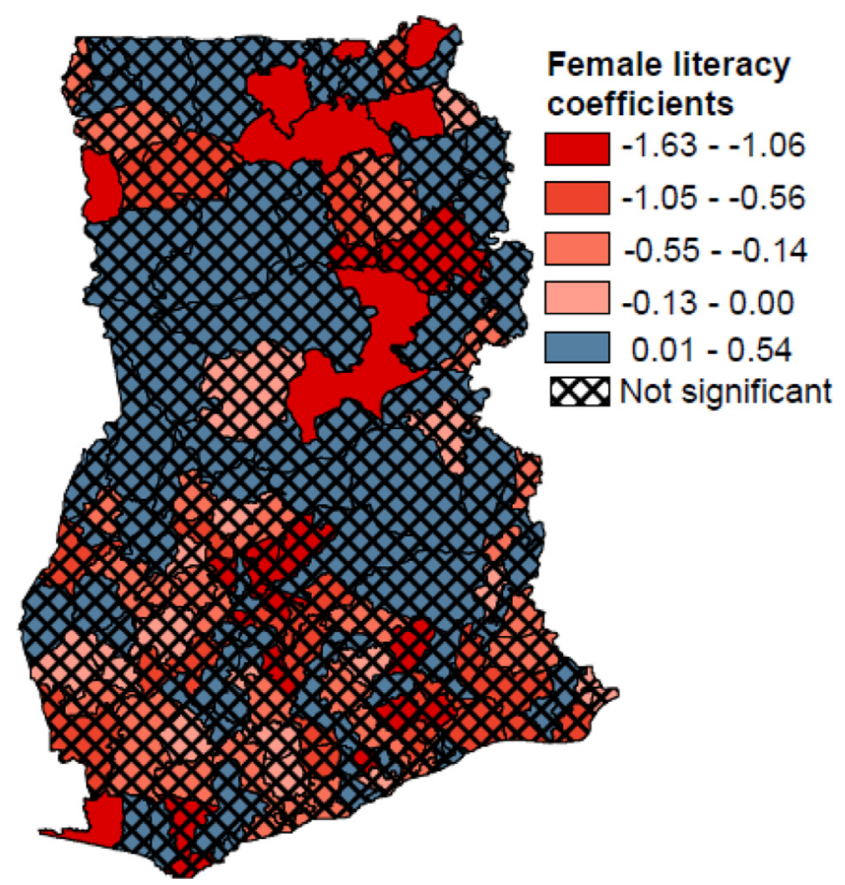

Fig. 12. Association between female literacy and academic performance. 
academic achievement $(b=0.17, p>.05)$. However, at the district level, this relationship is trending in a positive direction in 119 of the 170 districts, but is statistically significant in only four districts where the local coefficients range from 1.29 to 1.38 (see Fig. 11).

\section{Female literacy and academic achievement}

Results from the global OLS test shows that the relationship between female adult literacy rate and academic achievement is in the negative direction, although not statistically significant ( $b=-0.11, p>.05)$. In contrast, results from the local GWR tests shows that the direction of the relationship is mixed (see Fig. 12). At the .05 significance level, the relationship is statistically significant in only eight districts $(b=-1.39$ to -1.63$)$.

\section{Limitations and strengths}

This study has limitations. First, the lack of data on the latest district demarcations means that this study could not offer insights into outcomes in the recently created districts. Related to the above data limitation is the challenge of using predictors from different measurement occasions. Our preference for predictors measured in the same year was not feasible given the non-availability of data. Nonetheless, the temporal explanation of our results is valid because all predictors used in this study preceded the outcome variable. Second, because of the high correlation between the explanatory variables, we had to use recommended data reduction techniques to reduce the data. Although this approach is rigorous and recommended to address multicolinearity problems, it limited our ability to have more information about the direct connection between specific indicators and our outcome variable. Despite these limitations, the study's strengths are noteworthy. The use of the GWR analytical method improved the study's explanatory power, beyond that offered by traditional regression models. In addition, the use of thematic mapping made it possible to highlight geographical disparities in academic achievement in Ghana that have been ignored in many studies.

\section{Discussions and implications}

A key finding from this study is that a comparison across all 170 districts in Ghana showed that certain districts (mostly in the southwest region) have significantly more candidates passing the JHS exit exams. This finding implies that the locality where young people pursue their JHS education matters to a large extent in whether the students will qualify for senior high school. Although it is unrealistic to expect no variations would exist across districts, it is nevertheless concerning to have systematic variations whereby certain regions of the country clearly have advantages when it comes to passing the BECE exam. Further, this discrepancy suggests an uneven playing field exists for the young people who attend school in "unfavorable" or disadvantaged districts.

Of the three main geographical belts of Ghana (Northern, Middle, and Southern), the Northern Belt is systemically disadvantaged in terms of the proportion of candidates who pass the BECE. As shown in Fig. 1, the Northern Belt districts generally have smaller proportions of candidates who obtain passing scores and therefore, only a small percentage of pupils in the Northern Belt will be able to transition to senior high school. Given that this outcome is obviously skewed in favor the Middle and Southern Belts, something needs to be done differently from multiple fronts, including research, programing, and policy. More research on educational outcomes needs to focus on potential spatial variation. Although it is helpful for studies to offer insights into educational outcomes across the board it is equally important for studies to test the moderation effects of locality.
Another goal of this study was to offer insights into factors that contribute to geographical disparities in educational outcomes. As demonstrated by the spatial autocorrelation results in Figs. 1 and 2, the greater percentage of candidates from certain districts who pass their exams and qualify for senior high school is not a chance occurrence. Something must be different about those districts where significant proportions of candidates make a passing score. Overall, we found that as compared with school factors, sociodemographic factors were stronger drivers of academic achievement. For instance, results of the local coefficients revealed that whenever the relationship between household size and academic achievement was statistically significant, the relationship was inverse. This inverse relationship means the bigger the household size, the lower the number of students who earn a passing score on the BECE. This finding is consistent with past studies, and it aligns with the resources dilution model, which suggests the more children of school going-age in the household, the less time and resources the parents have for each child; deficits of parental time and resources invariably affect the children's educational outcomes (Downey, 1995).

We also found geographical disparities in the magnitude of the negative relationship between household sizes and academic achievement. Fig. 5 shows that most of the districts with a significant negative relationship between household size and academic achievement are in the Northern Belt of the country. Further, the figure illustrates that there are disproportionally darker red colors (higher negative coefficients) in the Northern Belt as compared with the Middle or the Southern Belt. This is an indication that although larger household size negatively affects academic achievement, the effect is more pronounced in deprived districts, which are mostly in the Northern Belt. The implication of this finding for policy and practice cautions that approaches to addressing lower educational standards have to be holistic. Larger household size may be primarily an economic or a health issue, but it also affects other dimensions of people's lives. That means, population and family planning programs or policies invariably affect the education of children in the household. Therefore, compelling reasons exist for Ghana's development agenda to have a broad scope that touches on varying dimensions of people's lives. The first major objective of the Ghana National Population Policy is clearly specified: "to integrate population issues into all aspects of the development planning process" (Ghana National Population Council, 1994). Significant efforts have been made in this regard, but more needs to be done at the district level. Such district-level efforts will allow District Assemblies faced with more serious population challenges to implement targeted programs that might be uniquely effective for their districts but not the country as a whole.

The study also found that while the overall level of urbanization of a district is not statistically related to academic achievement in the district, the importance of urbanization generally depends on the location of the district. Results of our analyses shown in Fig. 6 demonstrate that when the relationship reaches statistical significance, the relationship tends to be negative in the mostly deprived Northern Belt but positive in the Middle and Southern Belt. These mixed results are an indication that urban areas in the Northern Belt do not have the same level of resources as urban areas in other parts of the country. Thus, what matters most is the locality's extent of "urban advantage" and not merely living in an urban area because not all urban areas have good amenities. In order words, it is the resources and infrastructure in the urban areas that put urban dwellers at an advantage over rural dwellers. Merely living in an urban area may not be helpful unless the area has good and adequate resources and amenities. In fact, the local results for the electricity connectivity (shown in Fig. 7) support our contention 
that the urban advantage is the key factor. In districts where electricity connectivity is connected to academic achievement, the relationship is positive, including districts in the Northern Belt. In the Northern Belt, when more households live in urban areas, academic achievement goes down; however, in the same district, when more households are connected to electricity, academic achievement goes up.

Although residing in an urban area might provide certain advantages, living in an urban area is likely to entail just as many challenges. To cope with urban stresses, urban dwellers might need to expend more effort, time, and financial resources. For instance, in Ghana's heavily urbanized areas such as Accra and Kumasi, commuting to and from work takes substantial time; consequently, urban parents are away from their children longer hours than rural parents. When parents come home late after a long commute, they may not have enough opportunity to get involved in their children's homework and other educational needs. Our finding of a negative relationship between female adults' employment and academic achievement is a typical case-in-point where the limited presence of employed mothers at home may have negative effects on children's education. Research in Ghana suggests that home-based parental involvement helps children's academic achievement better than other forms of parental involvement (Chowa, Masa, \& Tucker, 2013).

These findings about the complicated urban dynamics have practical implications for families' residential choices and urban planning in Ghana. For families in the Northern Belt who have school-age children, it may be more important for the children to attend schools in districts with higher electricity connectivity or adequate access to amenities, regardless of whether the school is located in an urban or rural area.

\section{Conclusion}

A salient finding from this study shows the academic achievement of JHS pupils in Ghana depends on where pupils live and attend school. The existing geographical disparities primarily favor the districts in the Middle and Southern Belts of the country. However, our findings do not mean that every district in the north is worse off than the middle and southern districts and vice versa. Consequently, a one-size-fits-all intervention is unlikely to be appropriate for effective outcomes across the board. Factors that drive academic outcomes are not stationary, as they depend on locality of the district. To this end, Ghana's efforts to devolve the management and allocation of resources to the district level is a step in the right direction, but more needs to be done to strengthen the capacity of district assemblies to effectively manage district resources. When district assemblies are empowered, they would be able to tailor and direct development resources to where it is needed most. At the same time, proper oversight at the local level is essential to ensuring prudent investment in local needs.

\section{References}

Abraha, S., Beyene, A., Dubale, T., Fuller, B., Holloway, S., \& King, E. (1991). What factors shape girls' school performance? Evidence from Ethiopia. International Journal of Educational Development, 11, 107-118. http://dx.doi.org/10.1016/07380593(91)90036-8.

Akyeampong, K., Rolleston, C., Ampiah, J. G., \& Lewin, K. M. (2012). Access, transitions and equity in education in Ghana: Researching practice, problems and policy (Research Monograph No. 72). Brighton, United Kingdom: Consortium for Educational Access, Transitions and Equity (CREATE). Available online at http:/ www.create-rpc.org/pdf_documents/PTA72.pdf Accessed 12.01.15.

Annim, S. K., Mariwah, S., \& Sebu, J. (2012). Spatial inequality and household poverty in Ghana. Economic Systems, 36(4), 487-505. http://dx.doi.org/10.1016 j.ecosys.2012.05.002.

Ansong, D. (2013). The relationship between household economic resources and youth academic performance in Ghana: A multilevel structural equation modeling.
Doctoral dissertation, Paper 1194. Washington University in St. Louis. Available online at http://openscholarship.wustl.edu/etd/1194 Accessed 11.09.15.

Ansong, D., \& Chowa, G. A. N. (2013). Visual demonstration of academic performance and parental involvement in Ghana (YouthSave Research Brief 13-17). St. Louis, MO: Washington University, Center for Social Development. Available online at http://csd.wustl.edu/Publications/Documents/RB13-17.pdf Accessed 16.11.15.

Asiamah, F. (2010, July 12). Ghana: Basic school education ailing. Public Agenda. Available online at the AllAfrica website http://allafrica.com/stories/ 201007130486.html Accessed 12.01.15.

Barnes, S. A., Green, A., Orton, M., \& Bimrose, J. (2005). Redressing gender inequality in employment: the national and sub-regional policy 'fit'. Local Economics, 20, 154-167. http://dx.doi.org/10.1080/02690940500053325.

Chowa, G., Masa, R., \& Tucker, J. (2013). The effects of parental involvement on academic performance of Ghanaian youth: testing measurement and relationship using structural equation modeling. Children and Youth Services Review, 35, 2020-2030. http://dx.doi.org/10.1016/j.childyouth.2013.09.009.

Chowa, G., Masa, R., Wretman, C., \& Ansong, D. (2013). The impact of household possessions on youth's academic achievement in the ghana youth save experiment: a propensity score analysis. Economics of Education Review, 33, 69-81.

Daily Graphic. (2008, August 29). 2008 BECE results - 62 percent made it. Modern Ghana. Available online at http://www.modernghana.com/news2/180704/1/ 2008-bece-results-62-percent-made-it.html Accessed 28.11.15.

Dave, M. (2013). When the lights go on: Household electrification and educational outcomes in rural India. Master's thesis. Georgetown University. Retrieved from https://repository.library.georgetown.edu/bitstream/handle/10822/558641/ Dave_georgetown_0076M_12200.pdf?sequence=1.

Degue, J. (2012). Reversing the decline in academic performance at the BECE level in Volta region: the role of stakeholders. Modern Ghana News. Retrieved from http:/www.modernghana.com/news/417607/1/reversing-the-decline-inacademic-performance-at-t.html.

Doro, M. E. (2008). The development decade?: economic and social change in South Africa, 1994-2004. Choice, 45(6), 1022. Retrieved from http://search.proquest. com/docview/225735263? accountid $=14244$.

Downey, D. B. (1995). When bigger is not better: family size, parental resources, and children's educational performance. American Sociological Review, 60(5), 746-761.

Duncan, G. J., \& Raudenbush, S. W. (1999). Assessing the effects of context in studies of children and youth development. Educational Psychologist, 34, 29-41.

Eccles, J. S., \& Davis-Kean, P. E. (2005). Influences of parents' education on their children's educational attainments: the role of parent and child perceptions. London Review of Education, 3(3), 191-204.

Etsey, K. (2005). Causes of low academic performance of primary school pupils in the Shama Sub-Metro of Shama Ahanta East Metropolitan Assembly (SAEMA) in Ghana. Paper presented at the Regional Conference on Education in West Africa Dakar, Senegal 1st-2nd November, 2005.

Fotheringham, A. S., Brunsdon, C., \& Charlton, M. (2002). Geographically weighted regression: The analysis of spatially varying relationships. West Sussex, England: Wiley.

Ghana National Population Council. (1994). National population policy at a glance. Available online at http://www.npc.gov.gh/assets/ NationalPopulationPolicyataGlance.pdf Accessed 11.02.15

Ghana Statistical Service. (2014). Ghana living standards survey round 6 (GLSS 6): Main report. Available online at http://www.statsghana.gov.gh/docfiles/glss6/ GLSS6_Main\%20Report.pdf Accessed 11.02.15.

Glaeser, E. L. (1999). Learning in cities. Journal of Urban Economics, 46, 254-277. http://dx.doi.org/10.1006/juec.1998.2121.

Jiang, Z., \& Xu, B. (2014). Geographically weighted regression analysis of the spatially varying relationship between farming variability and contributing factors in Ohio. Regional Science Policy \& Practice, 6(1), 69-84. http://dx.doi.org/ $10.1111 /$ rsp3.12028.

Kunateh, M. A. (2011 June 23). Ghana: who cares about the north-south divide in standards of living?. The Ghanaian Chronicle. Available online at http://allafrica. com/stories/201106240076.html Accessed 03.01.15.

Ludwig, J. (1999). Information and inner city educational attainment. Economics of Education Review, 18, 17-30.

Maikish, A., \& Gershberg, A. (2008). Targeting education funding to the poor: Universal primary education, education decentralization and local level outcomes in Ghana (Document Code 2009/ED/EFA/MRT/PI/38). UNESCO. Available online at http://unesdoc.unesco.org/images/0018/001804/180410e.pdf Accessed 02.01.15.

Mereku, K. (2012). Should BECE mark the end of JHS education?. Available online at http://www.ghanaschoolsnet.com/forum/topics/should-bece-mark-the-end-ofjhs-education Accessed 14.11.14.

Michaelowa, K. (2001). Primary education quality in francophone Sub-Saharan Africa: determinants of learning achievement and efficiency considerations. World Development, 29, 1699-1716. http://dx.doi.org/10.1016/S0305-750X(01) 00061-4.

Ministry of Education (2013). Education sector performance report. Accra, Ghana: Ghana Ministry of Education. Available online http://www.moe.gov.gh/docs/ FinalEducationSectorReport-2013.pdf, Accessed 30.04.15

Nakaya, T. (2014). GWR4 User Manual: Windows application for geographically weighted regression modelling. Available online at https://geodacenter.asu.edu/ drupal_files/gwr/GWR4manual.pdf Accessed 23.10.14. 
Norviewu-Mortty, E. K. (2012). Principals' strategies for improving the academic achievement of students of disadvantaged rural Junior High Schools in Ghana (Doctoral Dissertations). Perth, Western Australia: Edith Cowan University. Available online at http://ro.ecu.edu.au/cgi/viewcontent.cgi? article $=1494 \&$ context $=$ theses Accessed 09.10.14

Rodríguez-Pose, A., \& Tselios, V. (2011). The determinants of regional educational inequality in Western Europe. In P. Nijkamp, \& L. Siedschlag (Eds.), Advances in Spatial Science SeriesInnovation, growth and competiveness - Dynamic regions in the knowledge-based world economy (pp. 135-163). Heidelberg, Germany: Springer.

Sampson, R. (2008). Moving to inequality: neighborhood effects and experiments meet social structure. American Journal of Sociology, 114(1), 189-231. http:// dx.doi.org/10.1086/589843.

Sampson, R. J., \& Morenoff, J. D. (1997). Ecological perspectives on the neighborhood context of urban poverty: past and present. In J. Brooks-Gunn, G. J. Duncan, \& J. L. Aber (Eds.), Neighborhood poverty (pp. 1-22). New York, NY: Russell Sage.

Savannah Accelerated Development Authority. (n.d.). About Savannah Accelerated Development Authority (SADA). Available online at http://www.sada-ghana.org/ about-sada Accessed 08.02.15
Senadza, B. (2012). Education inequality in Ghana: gender and spatial dimensions. Journal of Economic Studies, 39(6), 724-739. http://dx.doi.org/10.1108/ 01443581211274647.

Songsore, J. (2003). Towards a better understanding of urban change: Urbanization, national development and inequality in Ghana. Accra: Ghana Universities Press.

UNDP. (2015). Achieving universal primary education. Available online at http:/ www.gh.undp.org/content/ghana/en/home/mdgoverview/overview/mdg2/ Accessed 11.02.15.

United Nations Economic Commission for Africa, African Union, African Development Bank, \& United Nations Development Programme. (2014). MDG Report 2014: Assessing Progress in Africa toward the Millennium Development Goals Addis Ababa, Ethiopia: Economic Commission for Africa.

Varly, P., Cummiskey, C., Kline, T., \& Randolph, L. (2014). Ghana 2013 national education assessment technical report. RTI International. Available online at https:// www.eddataglobal.org/documents/index.cfm/2013\%20NEA\%20Technical\% 20Report_15May2014_wRecs.pdf?fuseaction=throwpub\&ID $=570 \quad$ Accessed 16.01.15.

Wheeler, C. H. (2004). Wage inequality and urban density. Journal of Economic Geography, 4, 421-437. http://dx.doi.org/10.1093/jnlecg/lbh033. 